\title{
Contribuições da gestão por competências para a eductação a distância: experimento com 0 ambiente AulaNet
}

Luís Henrique Raja Gabaglia Mitchell Hugo Fuks

Carlos José Pereira de Lucena

\section{Competency management contributions to distance education: experiment with the AulaNet environment}


Resumo: Este trabalho investiga como práticas empresariais de Gestão de Pessoas por Competências podem, enriquecidas com o embasamento teórico apropriado, ser transpostas para o mundo acadêmico com o objetivo de beneficiar a aprendizagem colaborativa a distância. O Modelo de Competências desenvolvido para - Ambiente AulaNet é apresentado como exemplo da infra-estrutura computacional necessária para o uso de práticas de gestão por competências no universo acadêmico. Em seguida, é divulgado um experimento que utilizou esta infra-estrutura para auxiliar a formação de grupos de trabalho em 3 turmas de graduação da PUCRio. Seus resultados demostraram que a formação de grupos por competências satisfez os aprendizes; que é possível estimar o desempenho de um grupo através das competências que ele reúne; e que comunicação, coordenação e cooperação, elementos imprescindíveis à colaboração, tem papel fundamental no resultado prático do trabalho dos grupos.

Palavras-chave: Gestão de Pessoas por Competências, Gestão do Conhecimento, Competências, Colaboração, Formação de Grupos

Abstract: This paper studies how e-learning, and collaborative learning in particular, can benefit from Competency Management practices. The Competencies Model developed for the AulaNet environment is shown as an example of the computational tools needed to manage competencies in the academia. The paper also presents an experiment with students at PUC-Rio where the model was used to form workgroups in 3 different classes. The results indicate that competency-based group formation was well accepted by the students and is useful to predict group performance, although the actual performance depends intrinsically on the 3 elements that encompass the definition of collaboration: communication, coordination and cooperation.

Keywords: Competency Management, Knowledge Management, Competency Model, Collaboration, Group Formation. 


\section{Introdução}

De acordo com The Economist [1996], cada ano a mais de estudos dos funcionários de uma empresa rende um aumento de produtividade de $8,5 \%$ no setor industrial e de $13 \%$ no de serviços. Pesquisas da $E$ Consulting [ITweb 2004] apontam que o valor gerado pelos ativos intangíveis (como o Conhecimento) já na próxima década irá ultrapassar o valor advindo dos ativos tangíveis (agro-industriais) na sociedade brasileira, transformando a atual relação $20 \%-80 \%$ para $65 \%-35 \%$. De fato, a crescente importância do Conhecimento como ativo econômico e diferencial competitivo tem levado as empresas a investir em práticas de como geri-lo para fazer frente à feroz competição globalizada da Nova Economia (COSTA, 2002). Sendo o Conhecimento resultado do processo cognitivo chamado Aprendizagem, em que a mente absorve informação e, interpretando-a, constrói um entendimento adicionado à rede de conhecimentos do cérebro (SIMON, 1991), gerir conhecimento é, em seu cerne, gerir as pessoas que o detêm e o constróem. Por isso, Gestão de Pessoas ganhou importância estratégica para as organizações atuais, sendo que a Gestão de Pessoas através de suas Competências - a manifestação externa e palpável do Conhecimento - é sua forma mais atual, adotada por várias empresas (COSTA, 2002).

Ao contrário dos bens tangíveis, ativos intangíveis podem ser indefinidamente compartilhados, num processo que até lhes agrega valor. Daí a importância da Colaboração. Paradoxalmente, justo quando a competição é maior, é por meio da Colaboração que as empresas e seus funcionários poderão se diferenciar. Empresas, ainda que com- petidoras em determinado setor da cadeia, poderão se unir e ser mais eficientes. É o exemplo de algumas empresas do setor jornalístico. Cada uma possuía seu próprio canal de distribuição para estar presente nos mesmos pontos de venda. Ao adotar um modelo colaborativo e compartilhar a mesma cadeia de distribuição, se tornaram mais competitivas e lucrativas (CALDAS, 2004).

Se o mundo corporativo está acordando para a necessidade de colaborar e gerir pessoas, seus conhecimentos e competências, o mundo acadêmico tem papel de destaque neste processo. Seja pesquisando metodologias e práticas, seja educando pessoas para esta nova realidade, seja estudando e prevendo conseqüências. Este trabaIho investiga como práticas empresariais de Gestão de Pessoas por Competências podem, enriquecidas com o embasamento teórico apropriado (seção 2), ser transpostas para o mundo acadêmico com o objetivo de beneficiar a aprendizagem colaborativa a distância. O Modelo de Competências desenvolvido para o Ambiente AulaNet é apresentado na seção 4, logo após uma breve descrição do ambiente em si e das premissas que guiaram seu desenvolvimento (seção 3 ). Na seção 5, é divulgado um experimento que utilizou esta infra-estrutura para auxiliar a formação de grupos de trabalho em 3 turmas de graduação da PUC-Rio. Seus resultados, comentados na conclusão do artigo (seção 6), demostraram que a formação de grupos por competências satisfez os aprendizes; que é possível estimar o desempenho de um grupo através das competências que ele reúne; e que comunicação, coordenação e cooperação, elementos imprescindíveis à colaboração, têm papel fundamental no resultado prático do trabalho dos grupos. 


\section{Em que a Gestão de Pessoas por Competências pode ser útil para a educação}

Para entender a utilidade da gestão de pessoas por competências, é antes necessário definir o que são competências. Em seu original latino, Competentia significava proporção, simetria (HOUAISS, 2001). Um indivíduo competente era aquele capaz de avaliar e agir adequadamente frente a uma determinada situação, tomando providências proporcionais à gravidade dos fatos ocorridos. Ampliando tal conceito, Perrenoud (2000) a define como a mobilização de recursos cognitivos (saberes, informações, valores, inteligências, esquemas de percepção e raciocínio) para solucionar um problema. Para Fleury \& Fleury (2001), numa visão mais voltada ao mercado, implica um saber agir (savoir faire) para agregar valor econômico à organização e valor social ao indivíduo. Comum às três visões estão as noções de que: a) Competência é um processo, cujos resultados podem ser medidos; e b) a Competência está indissociavelmente ligada à pessoa.

Toda vez que é instigado a agir, o indivíduo precisa aplicar adequadamente seus recursos cognitivos, sendo que a experiência coletada nas ações passadas influencia as decisões futuras. Este processo é permanente e é a ele que o termo Competência se refere. Cabe distinguir esta definição do conceito de Tópico, que é aquilo em que pessoas podem ser competentes. Por exemplo: "fluência em inglês nível intermediário" é um Tópico, enquanto que uma determinada pessoa saber este tópico é uma Competência. Aliás, na língua inglesa há mesmo duas palavras diversas que indicam esta sutil distinção: Competency significa Competência, enquanto que Competence se refere a Tópico. Ao longo deste texto, porém, o termo competência (em minúsculo) é usado tanto como Tópico quanto como Competência quando a distinção entre ambos os termos for irrelevante ao contexto.

Há uma série de questões que a Gestão de Pessoas por Competências busca responder. São perguntas advindas do mundo empresarial, onde a gestão de pessoas é mais usada como um meio para se alcançar os objetivos comerciais. O conjunto de tabelas a seguir mostra uma seleção das mais relevantes destas questões, porém alterando o foco para o mundo acadêmico, onde a gestão de pessoas é não é só um meio mas a própria finalidade da instituição de ensino, cujos membros que visa educar são, a um só tempo, clientes e colaboradores. Algumas perguntas puderam ser mantidas intactas, outras ganharam uma versão (com o sinal de apóstrofe logo após a numeração) específica para a academia.

Tabela 1: Questões sobre Mapeamento de Competências

\begin{tabular}{|c|c|c|}
\hline Área & & Questões \\
\hline \multirow{3}{*}{$\begin{array}{l}\text { Mapeamento } \\
\text { de } \\
\text { Competências }\end{array}$} & 1 & $\begin{array}{l}\text { Quais competências } \\
\text { existem na } \\
\text { organizagão? }\end{array}$ \\
\hline & 2 & $\begin{array}{l}\text { De que tipos? Qual a } \\
\text { releu ância de cada tipo? } \\
\text { Como estão } \\
\text { interligados? }\end{array}$ \\
\hline & 3 & $\begin{array}{l}\text { Como se relacionam com } \\
\text { a estrutura da } \\
\text { organiz ação? }\end{array}$ \\
\hline
\end{tabular}

Este primeiro grupo de questões monta a infra-estrutura do projeto de gestão por competências. Trata-se de estabelecer quais as competências relevantes para uma instituição. Para facilitar o entendimento, elas podem ser agrupadas em diversos tipos. A 
classificação depende da necessidade, mas alguns exemplos são: Gerenciais, Técnicas e Sociais (FONSECA, 2003), classificação voltada para a utilidade da competência; ou Diferenciais, Essenciais, Básicas e Terceirizáveis (GRAMIGNA,2002), onde a importância estratégica da competência para o negócio da empresa é o que conta.

Uma questão interessante a resolver é se competências podem ser formadas de outras competências. A resposta é que permitir esta composição de competências pode facilmente levar à confusão entre as pessoas que irão utilizar tal estrutura, posto que é difícil controlar em que nível da hierarquia uma competência deve se encontrar, bem como enxergar sutilezas no reuso de competências umas em outras. Por exemplo: uma competência "Triatlo" pode ser formada por "corrida", "natação" e "ciclismo". Ao criar a competência "Pentatlo", alguém pode resolver aproveitar, por exemplo, a "corrida", sem se dar conta que no Triatlo a corrida é uma maratona de $42 \mathrm{Km}$, ao passo que no Pentatlo é uma corrida rústica de $4 \mathrm{Km}$. Além disto, Pentatlo não pode ser composto de Triatlo mais 2 esportes, porque ciclismo não faz parte do Pentatlo. Mas a vontade de hierarquizar e compor competências poderia iludir as pessoas a cometerem tais erros. Logo, para se admitir um modelo em que competências são formadas por outras competências é preciso uma estrutura fácil de ser entendida, previamente estudada e claramente disseminada entre quem vá utilizá-la. Do contrário, é melhor ater-se a um modelo mais simples como, aliás, fazem iSOCO (2002), Avilar (2003) e também o modelo apresentado neste artigo (QuIP Model), que não permite composição de competências mas admite que as mesmas sejam agrupadas em Áreas de Conhecimento. Na prática, um segundo nível hierárquico, utilizado para mapear as competências à estrutura organizacional da instituição, como sugere a pergunta 3 .

Tabela 2: Questões sobre localização de experts e mentores

\begin{tabular}{|c|c|c|}
\hline Área & & Questỗes \\
\hline & 4 & $\begin{array}{l}\text { Quem é mais } \\
\text { habilitado para um } \\
\text { certo projeto? }\end{array}$ \\
\hline $\begin{array}{c}\text { Localização } \\
\text { de }\end{array}$ & 5 & $\begin{array}{l}\text { Quantas vezes um } \\
\text { perito ajudou } \\
\text { funcionários da } \\
\text { empresa? Em que } \\
\text { temas? Com qual } \\
\text { qualidade (avaliação } \\
\text { dos funcionários)? }\end{array}$ \\
\hline \multirow[t]{3}{*}{$\begin{array}{l}\text { Experts } \\
\text { e } \\
\text { Mentores }\end{array}$} & $5:$ & $\begin{array}{l}\text { Quantas vezes um } \\
\text { docente lecionou } \\
\text { um certo tema? } \\
\text { Para quantas }\end{array}$ \\
\hline & & $\begin{array}{l}\text { pessoas? } \\
\text { Com qual qualidade } \\
\text { (avaliagă dos } \\
\text { aprendizes)? }\end{array}$ \\
\hline & 6. & $\begin{array}{l}\text { Quantas e quais } \\
\text { pessoas um certo } \\
\text { mentor aconselha? }\end{array}$ \\
\hline
\end{tabular}

Encontrar a pessoa certa para o trabalho é o próximo passo das iniciativas de gerência de documentos que marcou o início das práticas de gestão do conhecimento. Agora, além de saber qual documento explica o que se deseja conhecer, procurase também quem é o perito no assunto. Do ponto de vista acadêmico, localizar um perito é conhecer as áreas de atuação e interesse dos pesquisadores na instituição. E a figura corporativa do mentor se traduz no papel de orientador, o docente encarregado de guiar o mestrado ou doutorado de alunos de pós-graduação ou os projetos de alunos da graduação. 
Tabela 3: Questões sobre formação de grupos para projetos

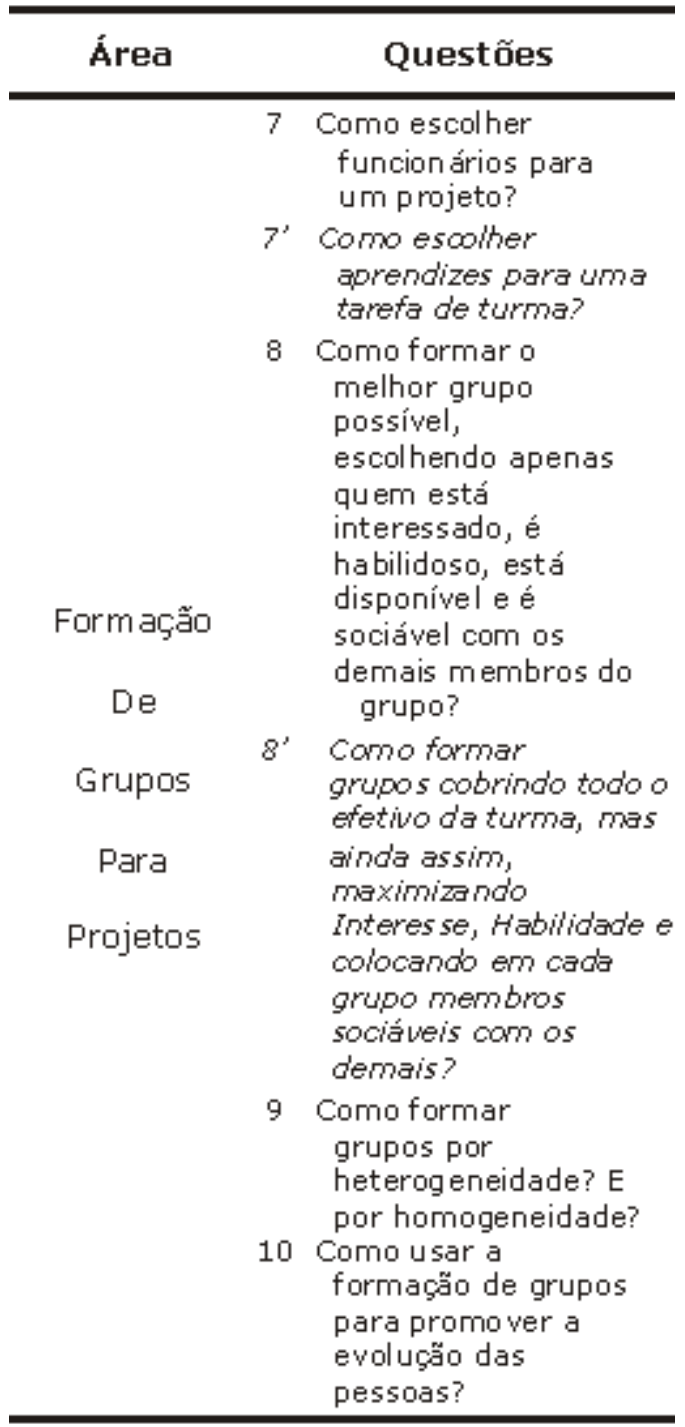

Nas empresas, a necessidade da formação de um grupo para cumprir certa tarefa geralmente induz a que se escolha os melhores funcionários disponíveis para aquele tipo de atividade, por vezes até contratando-se novos empregados para preencher as lacunas do grupo. No escopo de uma turma de aprendizes, ao contrário, é preciso formar não 1 grupo dos melhores, mas sim vários grupos com todos os integrantes das turmas. Já que todos devem participar, o problema é mais complexo. E é exatamente por isto que as questões deste conjunto foram escolhidas para compor o objeto de estudo do experimento descrito mais a frente neste artigo.

Tabela 4: Questões sobre Plano de Desenvolvimento Individual

\begin{tabular}{|c|c|}
\hline área & Questồes \\
\hline \multirow{7}{*}{ PDI } & $\begin{array}{l}11 \text { Como uma certa } \\
\text { pessoa evoluiu em } \\
\text { suas competêndas } \\
\text { ao longo do tempo? }\end{array}$ \\
\hline & $\begin{array}{l}12 \text { Que metas traçar } \\
\text { para um certo } \\
\text { funcionário para o } \\
\text { próximo ano? }\end{array}$ \\
\hline & $\begin{array}{l}12 \text { Que competências } \\
\text { um certo aprendiz deve } \\
\text { desenvolver para o } \\
\text { próximo } \\
\text { penodo letivo? }\end{array}$ \\
\hline & $\begin{array}{l}13 \text { Como ele pode se } \\
\text { preparar para } \\
\text { dumprir tais metas? }\end{array}$ \\
\hline & $\begin{array}{l}13^{\prime} \text { Que disciplinas } \\
\text { arsar para cumprir tais } \\
\text { metas? }\end{array}$ \\
\hline & $\begin{array}{l}14 \text { Quais os interesses } \\
\text { pessoais do } \\
\text { funcionário e como } \\
\text { isto se encaixa às } \\
\text { necessidades da } \\
\text { empresa? }\end{array}$ \\
\hline & $\begin{array}{l}144^{\prime} \text { Quais os abjetivos } \\
\text { do aprendiz com o curso? } \\
\text { o que ele deseja adquirir } \\
\text { emseu curricub que a } \\
\text { instituigão de ensino tem } \\
\text { a oferecer? }\end{array}$ \\
\hline
\end{tabular}

Enxergar as competências individuais permite aos docentes de uma disciplina planejar para cada aprendiz o desenrolar do período letivo. Medir o progresso dessas pessoas ao longo do tempo permite à orga- 
nização obter métricas de como seu esforço educacional está se traduzindo em resultados práticos, facilitando não só o planejamento do currículo de cada aprendiz mas também o próprio planejamento estratégico da companhia.

Planejar o currículo de uma pessoa significa traçar um PDI - Plano de Desenvolvimento Individual, instrumento usado nas corporações para que empregados, junto com seus mentores, planejem sua carreira na empresa em face dos interesses pessoais e das necessidades da companhia. $\mathrm{Na}$ sua versão acadêmica, o PDI reflete o histórico escolar do aprendiz e o currículo que ele deseja desenvolver, dentro das oportunidades oferecidas pela instituição. Principalmente em cursos onde a grade de disciplinas não é muito rígida, havendo espaço para matérias optativas e eletivas, o planejamento do currículo, inclusive com a ajuda de um professor orientador, é prudente para se alcançar os objetivos desejados.

Com os objetivos individuais traçados, a própria instituição como um todo pode agora estimar a demanda de disciplinas, planejando contratação, preparação ou remanejo de professores. A instituição de ensino caminha, assim, para adotar práticas de planejamento estratégico em sua própria administração. E bem administrar os recursos contribui para a busca da excelência pela instituição.

\section{Colaboração e o ambiente AulaNet}

O AulaNet surgiu em 1997 no Laboratório de Engenharia de Software (LES) do Departamento de Informática da PUC-Rio. É gratuito, com mais de 4500 cópias solicitadas em português, inglês e espanhol e, ao
Tabela 5: Questões sobre Planejamento Estratégico

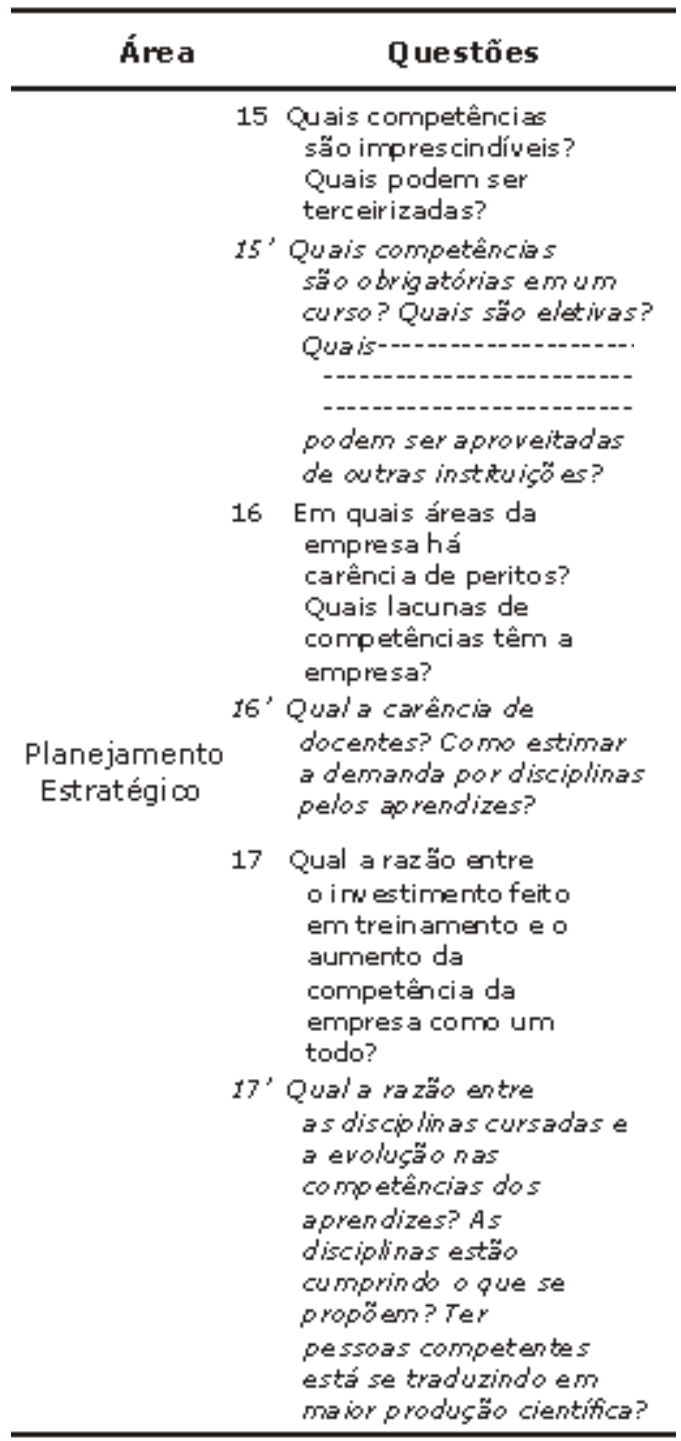

contrário da maioria das iniciativas deste tipo, conta com suporte especializado oferecido pela EduWeb (2003), empresa de projetos de e-learning constituída justamente para difundir o ambiente.

O AulaNet oferece a funcionalidade típica de um LMS (Learning Management System): apoio à criação e manutenção de 
cursos, participação nos mesmos e administração de aprendizes e matrículas. Porém, com o diferencial de ter sido planejado como ambiente para promover a Colaboração, que é o trabalho conjunto de duas ou mais pessoas visando alcançar resultados melhores do que os que seriam obtidos com a soma dos resultados de cada pessoa trabalhando isoladamente. Colaborando, os membros do grupo complementam seus conhecimentos e habilidades, identificando mais rapidamente inconsistências no raciocínio uns dos outros. Juntos, podem debater variadas possibilidades, gerando criativamente alternativas que são submetidas ao crivo do grupo. E evitam, ainda, a repetida mobilização dos mesmos recursos (TUROFF \& HILTZ, 1982). Para colaborar, as pessoas precisam se comunicar, coordenar suas atividades e cooperar em um mesmo espaço compartilhado, como mostra o modelo abaixo, adaptado de Ellis et al. (1991) e explicado detalhadamente em Fuks et al.( 2003):

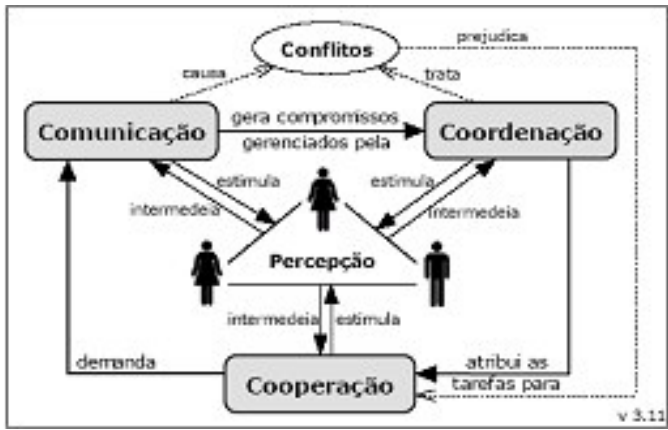

Figura 1: Modelo 3C de colaboração

Quando as pessoas se comunicam, trocando idéias a respeito de uma tarefa, assumem compromissos quanto a como resolver a tarefa. Tais compromissos precisam ser coordenados de modo a se garantir que sejam mesmo cumpridos e na ordem necessária. Cumprir os compromissos assumidos significa trabalhar, operando em conjunto. Esta cooperação requer comunicação, fechando o ciclo que é permeado pela percepção (awareness), ou seja, a aquisição de informações através dos sentidos (BRINCK e McDANIEL, 1997). Este modelo de colaboração serviu de arcabouço teórico para o AulaNet que, embora não obrigue quem o utiliza a necessariamente promover colaboração, é construído para apoiar iniciativas em aprendizagem colaborativa. Na prática, isto se traduz em serviços de comunicação, de coordenação e de cooperação oferecidos pelo ambiente. Uma explicação mais detaIhada destes serviços está em Fuks et al. (2003).

\section{QulP Model: o modelo de competências para o AulaNet}

A modelagem computacional de competências ainda não conta com um padrão estabelecido no mercado. O modelo aqui apresentado baseou-se na especificação RDCEO - Reusable Definition of Competency or Educational Objective - do IMS (2002), estendendo-o com elementos dos padrões HR-XML (2003), IEEE LOM Learning Object Metadata - (IEEE WG12 2003) e IEEE Metadata (IEEE WG20 2003), além de elementos próprios. A Figura 2, a seguir, mostra resumidamente uma parte do modelo de competências do AulaNet.

A figura está em inglês justamente para dar destaque à diferença entre Competence (Tópico) e Competency (Competência). Os Tópicos estão agrupados em Áreas de Conhecimento e se relacionam a Conteúdos. Relacionar Tópicos a Conteúdos é uma atividade dos docentes encarregados do cotidiano de uma disciplina (chamados de Mediadores, pois servem de ponte para a cons- 


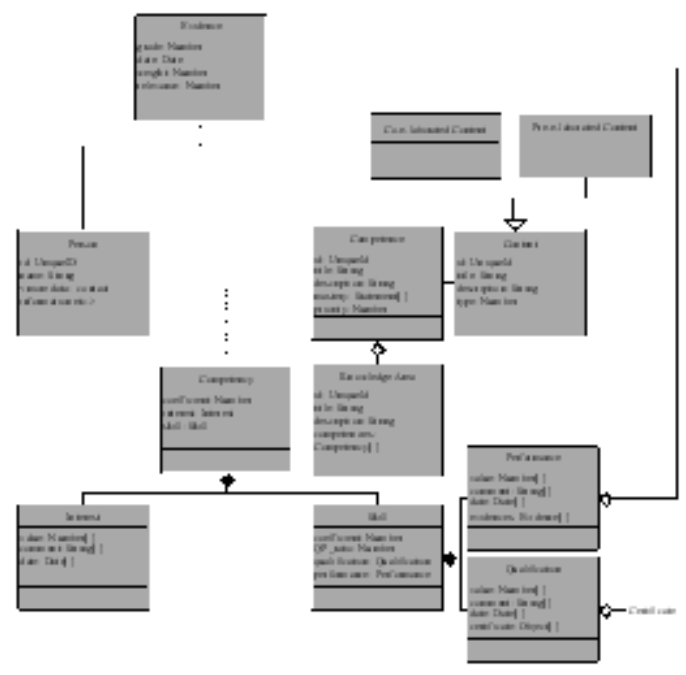

Figura 2: Estrutura do QuIP Model, o Modelo de Competências para o Ambiente AulaNet

trução de conhecimento pelos aprendizes). Eles escolhem quais dos tópicos da disciplina cada conteúdo trata, e com qual intensidade, como mostra a Figura 3 abaixo:

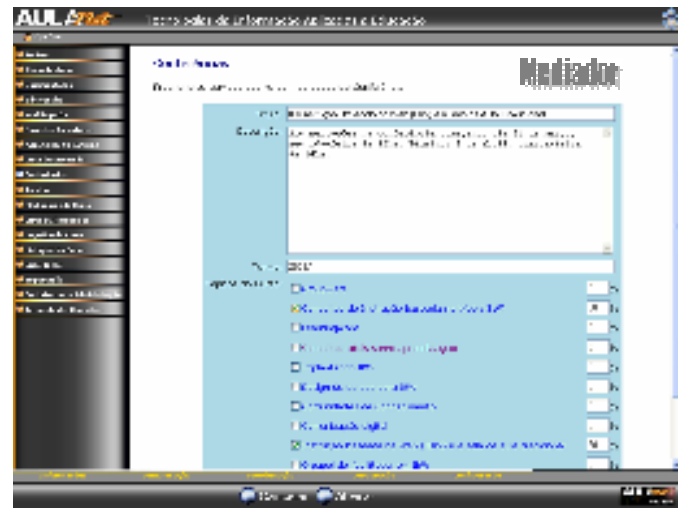

Figura 3: Associando tópicos aos conteúdos de uma disciplina

Conteúdos pré-elaborados são aqueles produzidos apenas por quem elaborou uma certa disciplina. Estão lá para o consumo dos aprendizes. São, por exemplo, aulas, documentações e bibliografias. Já conteúdos co-elaborados envolvem diretamen- te os próprios aprendizes da disciplina em sua confecção. São debates, conferências ou tarefas que formam a estrutura para que se dê a colaboração entre os integrantes de uma turma. Com os diversos conteúdos mapeados para os respectivos tópicos, o Coordenador da disciplina tem a seu dispor um relatório de quais tópicos existem na disciplina e quais conteúdos abordam estes tópicos. Assim, pode saber se o curso está incompleto, ou se há conteúdos fora de contexto. Pode, ainda, adicionar ou retirar da disciplina tópicos do ambiente, como mostra a Figura 4.

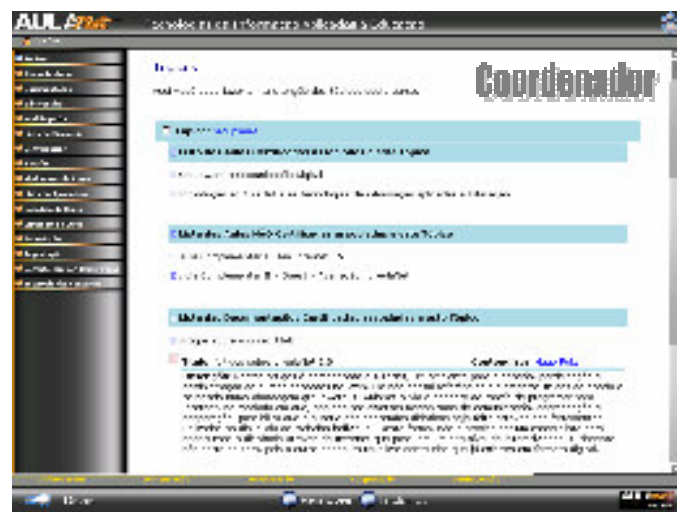

Figura 4: Relatório de Conteúdos por Tópicos

O relacionamento entre as pessoas e os Tópicos do ambiente forma as Competências individuais. Neste trabalho, o conceito de Competência não compreende apenas a Habilidade (Skill) de uma pessoa, mas também o Interesse (Interest) em trabalhar com assuntos envolvendo o tópico a que a competência se refere. Nisto se busca reconhecer que ser competente é antes de tudo estar interessado em exercer a competência na prática, como alerta Kellner (2002), ao considerar a atitude ou motivação das pessoas como pedra angular do processo de gestão. A Habilidade, por sua vez, é com- 
posta de Qualificação e Performance. O primeiro termo é uma declaração da própria pessoa, com o auxílio de seu mentor, sobre os conhecimentos adquiridos fora do ambiente, como cursos ou experiência profissional prévios. Esta declaração pode ou não ser fundamentada em documentos que atestem saber teórico ou prático, como diplomas ou certificados. A Performance, por sua vez, mede o desempenho do aprendiz ao longo de suas interações dentro do ambiente com os diversos conteúdos co-elaborados em que participou. Cada participação, avaliada por um mediador em uma disciplina, gera uma Evidência (Evidence), que irá compor a Performance. Quanto mais recente e abrangente a Evidência for, mais relevante ela será para o conceito da Performance (o cálculo matemático pode ser conferido em Mitchell (2003). E quanto maior for o número de evidências relevantes, mais confiável será a Performance. Enxergar uma Competência nestas 3 dimensões que a constituem é tão fundamental ao modelo que lhe deu seu nome: QuIP Model à Qualification, Interest, Performance.

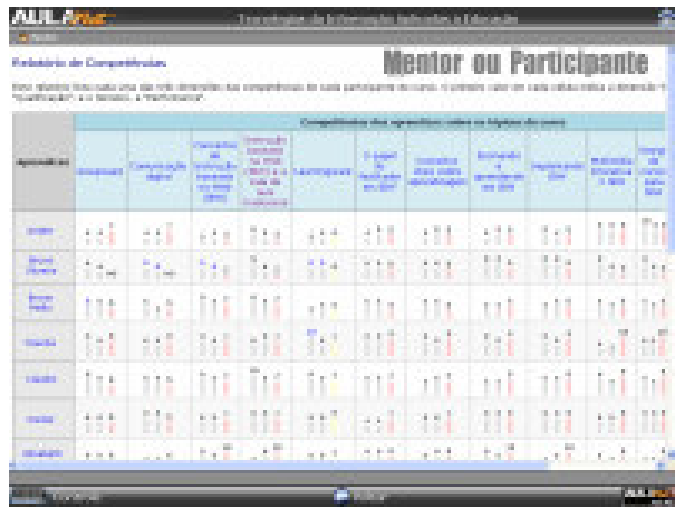

Figura 5: Relatório de Competências

A Figura 5, acima, mostra o Relatório de Competências disponível para os participantes de uma disciplina, mostrando os integrantes da turma. O mesmo tipo de relató- rio também pode ser conferido pelo mentor, em relação às pessoas sob sua orientação. Nele, é possível ver as 3 dimensões das competências de cada aprendiz, incluindo comentários de aprendizes e docentes nas qualificações e interesses, bem como o nível de confiabilidade das performances. Observe-se que em momento algum é mostrado um único valor para a competência de um aprendiz. Isto porque um coeficiente de competência único só faz sentido dentro do escopo de um objetivo para o seu uso.

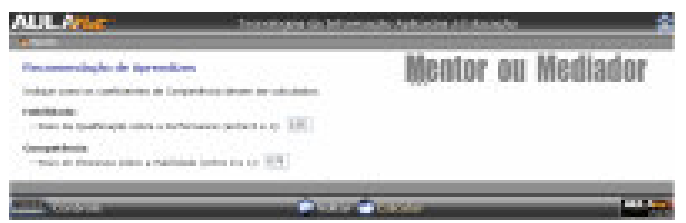

Figura 6: Preenchimento dos pesos para cálculo do Coeficiente de Competências

Por exemplo: quando um docente precisa dividir em grupos de trabalho sua turma de aprendizes, pode querer levar mais em consideração uma dimensão do que outra, dependendo das características da tarefa. Ao determinar pesos para as dimensões de competências, como mostra a Figura 6, acima, o docente faz com que o ambiente calcule um coeficiente de competência.

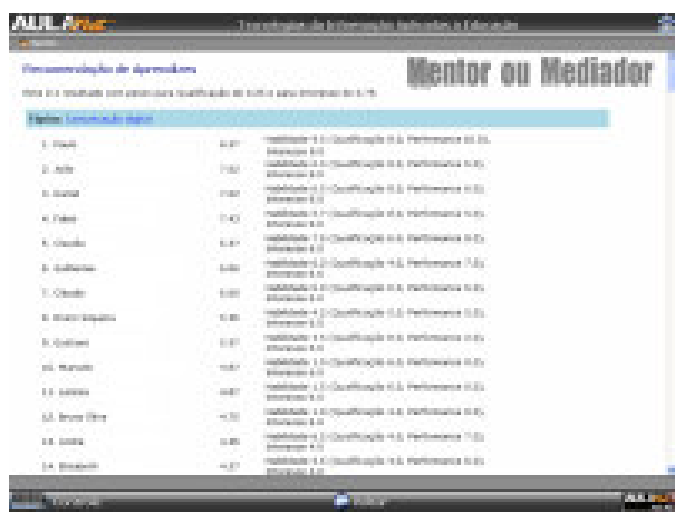

Figura 7: Recomendação de como formar os grupos com base nas competencies individuais 
Tal coeficiente é então utilizado para gerar um ranking de aprendizes para cada tópico, como visto acima, que serve como instrumento de apoio ao docente na decisão de como formar os grupos para a tarefa. $O$ docente pode optar por escolher os melhores para trabalhar em cada tópico, um misto entre competências, ou ainda qualquer outra estratégia que lhe seja conveniente. $\mathrm{Na}$ próxima seção, mostra-se 3 diferentes metodologias de formação de grupos usadas na prática e os resultados de cada uma.

\section{Experimento: formação de grupos por competências}

Tecnologias de Informação Aplicadas à Educação (TIAE) é uma disciplina da PUCRio ministrada inteiramente a distância, cujo objetivo de formar educadores para a era do e-learning implica na mudança de atitude de seus participantes para que deixem de ser alunos - pessoas sem luz que passivamente aguardam um professor lhes professar verdades - em prol da postura de aprendizes - pessoas ávidas por apreender coisas novas, construindo seu próprio conhecimento com o intermédio e estímulo de seus pares e de um mediador. A dinâmica da disciplina divide-se em duas etapas. Na primeira, os aprendizes discutem ativamente em conferências (comunicação assíncrona) e debates (comunicação síncrona) um par de tópicos da disciplina por semana, ao longo de 8 semanas. A participação de cada aprendiz é continuamente medida em sua quantidade e qualidade, gerando evidências para o cálculo da performance de cada um. $\mathrm{Na}$ segunda etapa, a turma é dividida em grupos para uma tarefa final onde cada grupo recebe a missão de gerar um conteúdo multimídia interativo sobre um dos pares de tópicos. Se o conteúdo gerado for de quali- dade, passará a integrar as versões futuras de TIAE. Para ajudar os mediadores a formar os grupos, um experimento foi realizado ao longo de 2003 com as turmas de TIAE do $1^{\circ}$ e $2^{\circ}$ semestres letivos. A título de comparação, uma outra disciplina, semipresencial e com uma estrutura de tópicos bem mais simples, foi também estudada. Trata-se de Informática para Ciências Humanas (Inf-CH), principalmente composta do estudo do pacote Microsoft Office: Word, Excel, PowerPoint e Access, que compunham os 4 tópicos da disciplina. Em cada turma, os mediadores adotaram diferentes metodologias de como formar os grupos. Mas todas partindo dos dados gerados pelo ambiente AulaNet, como visto na seção anterior, com Interesse valendo $75 \%$ do coeficiente de Competência, dado o desejo de privilegiar o interesse das pessoas sem descuidar de suas habilidades. A escolha deste peso (75\% Interesse vs. $25 \%$ Habilidade), especificamente, e não de outro com efeito próximo, como $60 \%-40 \%$ ou $90 \%-10 \%$, foi tomada a partir da simulação de vários cenários com a turma de TIAE 2003.1, cujos mediadores tinham a vantagem de conhecer pessoalmente os aprendizes, desde disciplinas anteriores e presenciais na própria PUC-Rio.

Em TIAE 2003.1, a estratégia usada para formar os grupos foi a seguinte:

1. Somar as competências de cada aprendiz em todos os tópicos da disciplina, criando um índice geral para cada pessoa;

2. Do maior índice geral para o menor, ordenar os aprendizes;

3. Começando com o primeiro aprendiz, colocá-lo no grupo de sua maior competência individual, exceto se o tópico não for importante para os mediadores. 
O resultado desta metodologia está na tabela abaixo, onde os números nas colunas "Ordem das Competências" são os rótulos dos pares de tópicos de TIAE, sendo que aqueles em negrito foram os designados para cada aprendiz. A coluna "Distância Competencial" expressa percentualmente a medida de quanto a competência do aprendiz para o grupo em que foi escolhido é menor que a maior de suas das competências. Por exemplo: naquilo em que é mais competente dos tópicos em pauta, certa pessoa tem coeficiente 10; se esta pessoa é alocada para uma tarefa que exija uma outra competência, onde seu coeficiente é 8, então dizse que a distância competencial é de $20 \%$. Isto é, a contribuição que a pessoa poderia dar para a turma está teoricamente reduzida em $20 \%$. É claro que estes números não podem ser considerados exatos, pois medem valores intangíveis. Tampouco é inteligente substituir pessoas por meros números. O que se deseja apenas é que eles sirvam como indicativo para auxiliar a tomada de decisões. No caso, a decisão de como dividir uma turma de aprendizes em grupos.

Tabela 6: Parte do rank para formação dos grupos de TIAE 2003.1

\begin{tabular}{|c|c|c|c|c|c|c|c|c|c|}
\hline \multirow{2}{*}{ Name } & \multirow{2}{*}{$\begin{array}{l}\text { indice } \\
\text { Genal }\end{array}$} & \multirow{2}{*}{$\begin{array}{c}\text { Distíncia } \\
\text { competencial }\end{array}$} & \multicolumn{7}{|c|}{ Ordem das Competincias } \\
\hline & & & 10 & 20 & 30 & 4 & s. & 60 & $77^{\circ}$ \\
\hline Jana & 51,2 & $0,20 \times$ & 7 & 3 & a & a & 2 & s & 4 \\
\hline Dam & 52,1 & o & a & a & 7 & 4 & 2 & 3 & 5 \\
\hline Luevaru & sas & $3,05 x$ & 4 & 5 & 7 & $\mathbf{3}$ & a & a & 2 \\
\hline Fansta & 47,9 & 0 & 7 & 2 & 3 & s & a & 4 & a \\
\hline Gatenal & $4 \mathrm{Q} 2$ & o & a & $\mathrm{s}$ & $\mathbf{3}$ & 4 & a & 2 & 7 \\
\hline Cisar & $44:$ & s,7rs & 3 & 4 & 7 & 2 & a & a & s \\
\hline Marcas & $4,1,1$ & $5, \mathrm{as}$ & 7 & 5 & a & a & 4 & 3 & 2 \\
\hline
\end{tabular}

Note-se que logo o primeiro colocado não foi colocado para trabalhar com o tópico em que era mais competente. Isto porque, na visão dos mediadores, o Tópico 3 era mais importante para a disciplina. Ou seja, os mediadores consideravam mais importante contar com novos conteúdos de qualidade feitos sobre o Tópico 3 do que sobre o Tópi- co 7. Considerando que a competência geral do aprendiz é mais elevada que a dos próximos da lista, os mediadores adotaram a suposição de que é melhor colocar o aprendiz de melhor competência nos grupos mais importantes. Tendo o bom senso, é claro, de checar através da distância competencial se não se desperdiçava muito das melhores competências do aprendiz.

A estratégia acima baseia-se na hipótese de que os grupos cujos integrantes têm menor distância competencial alcançarão melhores resultados. Na seção 5.1 esta hipótese é verificada.

Para TIAE 2003.2, a estratégia foi:

1. Classificar os tópicos da disciplina por ordem de importância para os mediadores;

2. Em cada tópico, escolher os aprendizes de maior coeficiente ainda não alocados em outros grupos.

Mais transparente, esta metodologia buscava alocar para os tópicos mais importantes os aprendizes de melhores coeficientes. Não necessariamente os melhores gerais, apenas os melhores naquele tópico em pauta. É inegável, contudo, que é comum que o melhor aprendiz em um tópico esteja também entre as primeiras escolhas para vários outros tópicos.

$\mathrm{Na}$ formação dos grupos de Inf-CH os tópicos da disciplina não tinham ordem de preferência. Assim, adotou-se uma estratégia para maximizar o aproveitamento das melhores competências individuais:

1. Ordenar em uma lista única as competências individuais em todos os tópicos (sem somá-las); 
2. Escolher as competências a partir das mais altas, alocando no grupo do tópico a que fazem referência a pessoa que a detém.

Esta abordagem busca diminuir a distância competencial, posto que a mais alta competência de um aprendiz será a primeira desta pessoa a figurar na lista de competências.

\subsection{Resultados}

A qualidade dos trabalhos finais em ambas as turmas de TIAE foi parecida. O conceito médio foi 6,9 em TIAE 2003.1 e 7,1 em TIAE 2003.2, com um desvio-padrão de 1,2 e de 1,3 respectivamente. As tabelas abaixo dão os detalhes para cada grupo, onde a Distância Competencial de um grupo é a soma daquela de seus membros.

Tabela 7: Conceitos e Competências das turmas de TIAE

\begin{tabular}{|c|c|c|c|}
\hline \multicolumn{4}{|c|}{ TIAE 2003.1} \\
\hline Grupo & \multicolumn{2}{|c|}{ Conceito $\begin{array}{c}\text { Média } \\
\text { dos } \\
\mathrm{C}_{\text {coet }}\end{array}$} & $\begin{array}{c}\text { Distância } \\
\text { Competencial }\end{array}$ \\
\hline $\mathrm{A}$ & 6,0 & 5,38 & $21,53 \%$ \\
\hline $\mathrm{B}$ & 6,8 & 7,60 & $4,10 \%$ \\
\hline c & 8,4 & 6,75 & $3,59 \%$ \\
\hline D & 8,8 & 7,81 & $3,25 \%$ \\
\hline $\mathrm{E}$ & 8,0 & 8,25 & 0 \\
\hline $\mathrm{F}$ & 6,0 & 8,08 & 0 \\
\hline G & 6,0 & 3,98 & $24,79 \%$ \\
\hline \multicolumn{4}{|c|}{ TIAE 2003.2 } \\
\hline Grupo & Conceito & $\begin{array}{l}\text { Média } \\
\text { dos } \\
\text { Conef }_{\text {coef }}\end{array}$ & $\begin{array}{l}\text { Distância } \\
\text { competencial }\end{array}$ \\
\hline A & 7,0 & 8,02 & $7,42 \%$ \\
\hline $\mathrm{B}$ & 9,0 & 8,28 & $2,94 \%$ \\
\hline C & 6,5 & 7,06 & $0,81 \%$ \\
\hline D & 5,0 & 7,86 & $7,28 \%$ \\
\hline E & 7,5 & 6,32 & $7,76 \%$ \\
\hline $\mathrm{F}$ & 6,5 & 4,45 & $37,06 \%$ \\
\hline
\end{tabular}

$\mathrm{Na}$ turma do 20 semestre havia menos aprendizes tendo, por isso, um grupo a menos
Observe-se que, em geral, os melhores conceitos pertencem aos grupos com os maiores coeficientes de competências e com as menores distâncias percentuais. Era o esperado, porém há exceções, como o grupo $\mathrm{F}$ em TIAE 2003.1 e o grupo $\mathrm{C}$ em TIAE 2003.2. Isto ocorre porque há fatores de ordem prática que influenciam a concretização da competência no produto final desejado. O gráfico seguinte mostra, por exemplo, como o tempo que cada grupo de TIAE 2003.1 dedicou ao trabalho (tempo de cooperação) teve influência direta no resultado final. Os dados do gráfico foram fornecidos pelos próprios aprendizes, em um questionário após a tarefa, sendo que ninguém do grupo $\mathrm{F}$ respondeu às perguntas propostas, fato que, em si, sugere também a falta de comunicação e coordenação das atividades do referido grupo.

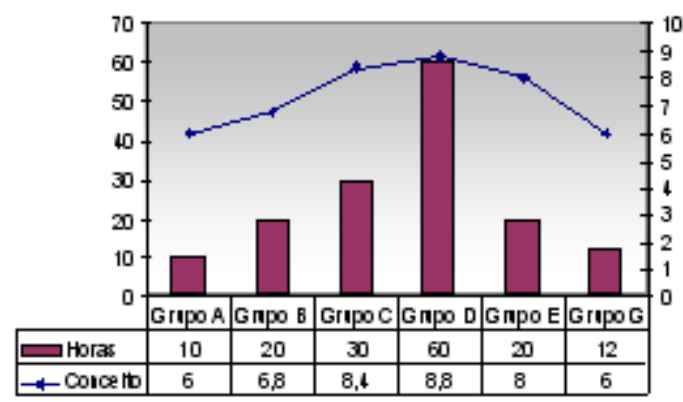

Figura 8: Relação Qualidade do Resultado vs. Horas de Trabalho

Para checar se a comunicação e a coordenação entre os aprendizes influenciava realmente nos resultados, o experimento com a turma de Inf-CH foi desenvolvido da seguinte maneira: os membros de cada grupo não podiam se encontrar presencialmente para trabalhar na tarefa relativa ao tópico do grupo. Assim, precisaram trocar mensagens entre si para escolher o tema do 
Tabela 4: Desempenho dos grupos de Inf-CH

\begin{tabular}{cc|c|cc|c}
\hline Grupo & Conceito & $\begin{array}{c}\text { Qtde. } \\
\text { Mensagens }\end{array}$ & $\begin{array}{c}\text { Horas de } \\
\text { Trabalho }\end{array}$ & $\begin{array}{c}\text { Média } \\
\mathbf{G}_{\text {coef }}\end{array}$ & $\begin{array}{c}\text { Distância } \\
\text { Competencial }\end{array}$ \\
\hline A & 9,0 & 25 & 35 & 9,8 & 0 \\
B & 7,5 & 16 & 15 & 6,0 & $8,25 \%$ \\
\hline C & 10,0 & 30 & 20 & 8,8 & 0 \\
\hline D & 0 & 0 & 0 & 1,5 & $6,25 \%$ \\
\hline
\end{tabular}

trabalho, dividir atividades e acompanhar o progresso de cada pessoa. Esta comunicação para a coordenação foi medida, como mostra a tabela abaixo:

Mais uma vez, os melhores conceitos se alinharam com altos coeficientes de competência e com baixas distâncias percentuais. E o sucesso dos grupos também dependeu da intensidade da interação entre seus membros: quanto maior o número de mensagens trocadas, melhor foi o conceito.

\section{Conclusão}

Cada Competência, formada pelo tripé Qualificação, Interesse e Performance, é um processo onde a habilidade passada e o interesse presente de um indivíduo são usados para estimar seu desempenho em uma atividade futura. A gestão destas competências, entre outros fins, provê apoio à formação de grupos de trabalho para projetos. Isto é útil para disciplinas integralmente a distância, como TIAE, posto que mediadores e aprendizes não se conhecem presencialmente. Mas também ajuda nas disciplinas eminentemente presenciais, como Inf- $\mathrm{CH}$, visto darem aos aprendizes a chance de declararem seus interesses e habilidades, sendo agrupados com colegas cuja competência poderiam desconhecer e que passaria despercebida dada a dificuldade de familiarizar-se em pouco tempo com todos na turma, mesmo em turmas razoavelmente pequenas.

Perguntados nos questionários póstarefa, $65 \%$ a $100 \%$ dos aprendizes em cada turma demonstraram satisfação com a estratégia de formar grupos privilegiando o interesse das pessoas sem descuidar de suas habilidades. As regras específicas usadas em TIAE 2003.1 - formar um ranking geral com o somatório das competências - e em TIAE 2003.2 - seguir a ordem de prioridade dos tópicos - geraram resultados semelhantes em termos de satisfação dos aprendizes e qualidade dos trabalhos entregues. Também o aproveitamento das competências pessoais foi parecido, como demonstra a proximidade entre os valores de distância competencial média em cada turma: 9,3\% e $10,5 \%$, respectivamente. Já a regra de formação de grupos usada em Inf-CH - escoIher os maiores coeficientes individuais independentemente dos tópicos - levou aos maiores valores de aproveitamento das competências individuais, com distância competencial média de apenas 3,1\%. Mas só foi possível porque todos os tópicos tinham a mesma importância.

Coeficientes de competências e suas distâncias percentuais serviram como indi- 
cador para se estimar o desempenho dos grupos. Porém, o resultado real do trabalho em grupo depende de outros fatores na prática, dentre os quais o tempo empregue na realização da tarefa em si (cooperação) e a intensidade da comunicação e coordenação entre os membros do grupo. São, de fato, os fatores que compõem a colaboração.

Referências

AVILAR TECHNOLOGIES Inc. 2003. WebMentor Skills. Disponível em: <http://www.avilar.com> Acesso em: jan. 2004.

BRINCK, T.;MCDANIEL, S. E. Awareness in Collaborative Systems. Workshop Report, SIGCHI Bulletin, 1997.

CALDAS, M. Mito ou Realidade? 2004. Disponível em: <http://www.informationweek.com.br/noticias/ artigo. asp?id=45912> Acesso em: 05 jan. 2004.

COSTA, T. e-RH: o impacto da tecnologia para a gestão competitiva de Recursos Humanos. USP-SP: Faculdade de Administração, 2002.

EDUWEB, 2003. Disponível em: <http://www.eduweb.com.br> Acesso em: jan. 2004.

ELLIS, C.A.; GIBBS, S.J.; REIN, G.L. Groupware - Some Issues and Experiences.

Communications of the ACM 34, (1), 38-58, 1991.

FLEURY, A.; FLEURY, M. T.. Estratégias Empresariais e Formação de Competências. São Paulo: Atlas, 2001.

FONSECA, D. Conceitos de Competências. Material do curso de Pós-graduação Lato Sensu em Gestão do Conhecimento e Inteligência Empresarial do C.R.I.E. - Centro de Referência em Inteligência Empresarial, 2003. Disponível em <http://www.crie.ufrj.br/index.html> Acesso em: jan. 2004.

FUKS, H.; RAPOSO, A.B.;GEROSA, M.A. Do Modelo de Colaboração 3C à Engenharia de Groupware. Simpósio Brasileiro de Sistemas Multimídia e Web - Webmidia 2003, Trilha especial de Trabalho Cooperativo Assistido por Computador. Salvador, BA, 03 a 06 de Novembro de 2003.

GRAMIGNA, M. R.. Modelo de Competências e Gestão dos Talentos. São Paulo: Makron Books, 2002. HOUAISS, A.. Dicionário da Língua Portuguesa. Rio de Janeiro: Objetiva, 2001.

HR-XML ASSOCIATION. Competencies Specification Release 26Feb.2003. Disponível em :<http:// ns.hr-xml.org/2_0/HR-XML-2_0/CPO/Competencies.pdf> Acesso em: jan. 2004.

IEEE LOM Working Group (WG12). 2003. Disponível em: <http://tsc.ieee.org/wg12/index.html> Acesso em: jan. 2004.

IEEE Competency Working Group (WG20). 2003. Disponível em: <http://ltsc.ieee.org/wg20/ index.html> Acesso em: jan. 2004.

IMS CONSORTIUM. RDCEO Specification. 2002. Disponível em: <http://www.imsproject.org> Acesso em: jan. 2004

ISOCO - INTELLIGENT SOFTWARE COMPONENTS S.A. Skills Management in KnowledgeIntensive Organizations. Abril 2002. Disponível em: <http://www.isoco.com> Acesso em: jan. 2004. 
ITweb Gestão do conhecimento será referência na economia do intangível 2004. Disponível em: <http://www.itweb.com.br/noticias/artigo.asp?id=47423> Acesso em: jan. 2004.

KELLNER, H. STAR: Sales Talent Assessment Review. Institute of Training and Development. Carlsbad, CA, USA. 2002. Disponível em: <http://www.usou.edu> Acesso em: jan. 2004.

MITCHELL, L.H.R.G.; FUKS, H.; LUCENA, C.J.P. Extensão de modelos de competências para avaliação formativa e continuada e planejamento de recursos humanos. XIV Simpósio Brasileiro de Informática na Educação - SBIE 2003, Rio de Janeiro, 12 a 14 de novembro de 2003.

PERRENOUD, P.. Novas Competências para Ensinar. Porto Alegre: Artmed, 2000.

TUROFF, M. \& HILTZ, S.R. Computer Support for Group versus Individual Decisions. IEEE Transactions on Communications 30, (1), 82-91.1982.

Recebido em março de 2004

Aceito para publicação em outubro de 2004

Luís Henrique Raja Gabaglia Mitchell

Mestre em Informática, pesquisador do Laboratório de Engenharia de Software (LES) da PUC-Rio

E-mail: raja@les.inf.puc-rio.br

\section{Hugo Fuks}

Doutor em Informática, professor associado da PUC-Rio

E-mail: hugo@inf.puc-rio.br

\section{Carlos José Pereira de Lucena}

Doutor em Informática, professor titular da PUC-Rio, coordenador do LES.

E-mail: lucena@inf.puc-rio.br

Demais trabalhos dos autores no site www.les.inf.puc-rio.br/groupware 